\title{
MHD Boundary Layer Flow of Heat and Mass Transfer over a Stretching Sheet in a Rotating System with Hall Current
}

\author{
M. Ali ${ }^{1 *}$, M. S. Alam ${ }^{1}$, M. Z. U. Chowdhury ${ }^{2}$, M. A. Alim ${ }^{3}$ \\ ${ }^{1}$ Department of Mathematics, Chittagong University of Engineering and Technology, \\ Chittagong, Chittagong-4349, Bangladesh \\ ${ }^{2}$ Planning and Monitoring Division, Bangladesh oil, Gas and Mineral Corporation, Dhaka, \\ Bangladesh \\ ${ }^{3}$ Department of Mathematics, Bangladesh University of Engineering and Technology, \\ Dhaka-1000, Bangladesh
}

Received 1 October 2015, accepted in final revised form 17 January 2016

\begin{abstract}
The present paper is an investigation of steady MHD free convection, heat and mass transfer flow of an incompressible electrically conducting fluid over a stretching sheet in a rotating system under the influence of an applied uniform magnetic field with Hall current. The governing equations are transformed to a system of non-linear ordinary differential equations which are then solved numerically by the shooting method. The numerical results concerned with the primary velocity, secondary velocity, temperature and concentration profiles, effects of various parameters on the flow fields are investigated and presented graphically. The results presented graphically illustrate that primary velocity field decrease due to increase of rotational and magnetic parameter but reverse results arises in case of Hall and heat generation parameter while secondary velocity decrease for stretching parameter and increase for Hall, rotational and magnetic parameter. The thermal boundary layer decreases for the increasing values of mentioned parameter. Also, concentration profiles decreases for increasing the values of magnetic parameter, rotational parameter, reaction parameter and Schmidt number but increases for heat generation and Dufour number. Finally, the numerical values of the skin friction, wall temperature gradient and concentration gradient are also shown in a tabular form.
\end{abstract}

Keywords: MHD; Stretching sheet; Rotational effect; Hall current.

() 2016 JSR Publications. ISSN: 2070-0237 (Print); 2070-0245 (Online). All rights reserved. doi: http://dx.doi.org/10.3329/jsr.v8i2.25197 J. Sci. Res. 8 (2), 119-128 (2016)

\section{Introduction}

When an electrically conducting fluid like mercury, molten iron and ionized gases are under the influence of magnetic field then this is called Magneto hydrodynamics

* Corresponding author: ali.mehidi93@gmail.com 
(MHD) flow. Therefore, in presence of magnetic field two cases arise such as an electric current is induced and this current experiences a force known as Lorentz force and secondly a magnetic field is induced which is added to the primitive magnetic field. MHD laminar boundary layer flow problems has important applications in industrial manufacturing processes like plasma studies, petroleum industries, MHD power generator, cooling of nuclear reactors, boundary layer control in aerodynamics. Also , MHD laminar boundary layer behavior over a stretching surface is a significant type of flow having considerable practical applications in paper production, hot rolling, wire drawing, drawing of plastic films, metal and polymer extrusion, metal spinning and polymer processing. MHD of rotating fluids is highly important due to its varied and wide applications in the areas of Geophysics, Astrophysics and fluid engineering. An order of magnitude analysis shows that in the basic field equations, the effects of coriolis force are more significant compared to that of inertial forces. Furthermore, it may be noted that the coriolis force and MHD forces are comparable in magnitude and coriolis force induces secondary flow in the fluid. The unsteady flow of a rotating viscous fluid in a channel maintained by non-torsional oscillations of one or both the boundaries has been studied by several authors to analyze the growth and development of boundary layers associated with geothermal flows for possible applications in geophysical fluid dynamics. In this regard, recently, Alam et al. [1] has investigated the heat and mass transfer on steady MHD free convection flow along an inclined stretching sheet with suction and heat generation, Rahman et al. [2] studied the effect of joule heating on MHD mixed convection around a heat conducting horizontal circular cylinder in a rectangular lid-driven cavity, Kuiry and Bhadur [3] has analyzed the effect of inclined magnetic field of viscous fluids between two parallel porous plates with heat transfer, Ahmmed et al. [4] studied the MHD natural convection flow of fluid from a vertical flat plate considering temperature dependent viscosity, Reddy [5] has studied the influence of MHD and thermal radiation boundary layer flow of a nanofluid past a stretching sheet, Kumar et al. [6] has studied the mathematical modeling of Soret and hall effects on oscillatory MHD free convective flow of radiating fluid in a rotating vertical porous channel filled with porous medium, Alam et al. [7] studied the effect of chemical reaction and magnetic field on free convection boundary layer flow of heat and mass transfer with variable Prandtl number, Parvin et al. [8] studied the effect of Prandtl number on forced convective flow and thermal field characteristics inside an open cavity with porous wavy isothermal wall using water-CuO nanofluid, Alam et al. [9] has analyzed the steady MHD boundary layer free convective heat and mass transfer flow over an inclined porous plate with variable suction and Soret effect in presence of hall current, Mishra [10] has investigated the heat and mass transfer in the flow of a viscous incompressible fluid along a vertical isothermal unsteady stretching sheet in the presence of heat generation and a transverse magnetic field. In view of the importance of rotating flows, in this paper, steady MHD free convection, heat and mass transfer flow of an incompressible electrically conducting fluid over a stretching sheet in a 
rotating system under the influence of an applied uniform magnetic field with Hall current is investigated. The ordinary differential equations are obtained by similarity transformations which are solved numerically using the fourth-order Runge-Kutta integration scheme along with shooting method. The results presented graphically illustrate that primary velocity field decrease due to increase of rotational and magnetic parameter but reverse results arises in case of Hall and heat generation parameter while secondary velocity decreases for stretching parameter and increases for Hall, rotational and magnetic parameter. The thermal boundary layer decreases for the increasing values of mentioned parameter. Also, concentration profiles decrease with the increase of magnetic parameter, rotational parameter, reaction parameter and Schmidt number but increases for heat generation and Dufour number.

\section{Mathematical Formulation and Governing Equations of the Problem}

Let us consider steady two dimensional MHD free convection heat and mass transfer in an incompressible electrically conducting fluid flow over a stretching sheet in a rotating system under the influence of an applied uniform magnetic field with Hall current. The flow is subjected to a transverse magnetic field of strength $B_{0}$ which is assumed to be applied in the positive $y$-direction normal to the surface. The pressure gradient, body force, viscous dissipation and joule heating effects are neglected compared with effects of internal heat source/sink. Under the above assumptions and usual boundary layer approximation, the dimensional governing equations of continuity, momentum, concentration and energy under the influence of externally imposed magnetic field in the presence of Hall current are: the uniform plate temperature $T w(>T \infty)$, where $T_{\infty}$ is the temperature of the fluid far away from the plate. Let $u, v$ and $w$ are the velocity components along the $X$ and $Y$ axis and secondary velocity component along the $Z$ axis respectively in the boundary layer region. Under the above assumptions and usual boundary layer approximation, the dimensional governing equations of continuity, momentum, energy and concentration under the influence of externally imposed magnetic field are:

Equation of continuity:

$\frac{\partial u}{\partial x}+\frac{\partial v}{\partial y}=0$

Momentum equation:

$$
\begin{aligned}
& u \frac{\partial u}{\partial x}+v \frac{\partial u}{\partial y}=U \frac{\partial U}{\partial x}+v \frac{\partial^{2} u}{\partial y^{2}}+g \beta\left(T-T_{\infty}\right)+g \beta^{*}\left(C-C_{\infty}\right)-\frac{\sigma B_{0}^{2}}{\rho\left(1+m^{2}\right)}(u+m w) \\
& +2 \Omega w \\
& u \frac{\partial w}{\partial x}+v \frac{\partial w}{\partial y}=v \frac{\partial^{2} w}{\partial y^{2}}+\frac{\sigma B_{0}^{2}}{\rho\left(1+m^{2}\right)}(m u-w)-2 \Omega u
\end{aligned}
$$


Energy Equation:

$u \frac{\partial T}{\partial x}+v \frac{\partial T}{\partial y}=\frac{k}{\rho c_{p}} \frac{\partial^{2} T}{\partial y^{2}}-\frac{Q_{0}}{\rho c_{p}}\left(T-T_{\infty}\right)+\frac{D_{m} K_{T}}{c_{s} c_{p}} \frac{\partial^{2} c}{\partial y^{2}}$

Concentration Equation:

$$
u \frac{\partial c}{\partial x}+v \frac{\partial c}{\partial y}=D_{m} \frac{\partial^{2} c}{\partial y^{2}}-k_{0}\left(C-C_{\infty}\right)+\frac{D_{m} K_{T}}{T_{m}} \frac{\partial^{2} T}{\partial y^{2}}
$$

Boundary conditions are:

$u=a x, v=0, w=0, T=T_{w}, C=C_{w}$ at $y=0$,

$u=U=b x, v=0, T=T_{\infty}, C=C_{\infty}$ as $y \rightarrow \infty$

To convert the governing equations into a set of similarity equations, we introduce the following similarity transformation:

$w=a g_{0}(\eta), \eta=y \sqrt{\frac{a}{2 v x}}, \psi=\sqrt{2 v x a} f(\eta), \theta(\eta)=\frac{T-T_{\infty}}{T_{w}-T_{\infty}}, \varphi(\eta)=\frac{C-C_{\infty}}{C_{w}-C_{\infty}}$,

$u=\frac{\partial \psi}{\partial y}, v=-\frac{\partial \psi}{\partial x}$

where, a $(>0)$ is a constant

By using the above transformations, the Eqs. (2) - (5) are reduced to non-dimensional, nonlinear and coupled ordinary differential equations:

$$
\begin{aligned}
& f^{\prime \prime \prime}+f f^{\prime \prime}+G r \theta+G m \varphi-\frac{M}{1+m^{2}} f^{\prime}+\left(R-\frac{M m}{1+m^{2}}\right) g_{0}+A+A^{2}=0 \\
& g_{0}^{\prime \prime}+f g_{0}^{\prime}-\frac{M}{1+m^{2}} g_{0}+\left(R+\frac{M m}{1+m^{2}}\right) f^{\prime}=0 \\
& \theta^{\prime \prime}+\operatorname{Pr} f \theta^{\prime}-Q \theta+D_{f} \varphi^{\prime \prime}=0 \\
& \varphi^{\prime \prime}+\operatorname{Scf} \varphi^{\prime}+S_{0} \theta^{\prime \prime}-S c \lambda \varphi=0
\end{aligned}
$$

The transform boundary conditions:

$f=0, f^{\prime}=1, g_{0}=0, \theta=\varphi=1$ at $\eta=0, f^{\prime}=A, g_{0}=\theta=\varphi=0$ as $\eta \rightarrow \infty$ 


\section{Results and Discussion}

The system of ordinary differential Eqs. (6) - (9) subject to the boundary conditions is solved numerically by Runge-Kutta fourth-fifth order method using symbolic software. First of all, higher order non-linear differential Eqs. (6) - (9) are converted into simultaneous linear differential equations of first order and they are further transformed into initial value problem by applying the shooting technique. Numerical calculation for distribution of the primary velocity, secondary velocity, temperature and concentration profiles across the boundary layer for different values of the parameters are carried out. Figs. 1 - 4 show the primary velocity profile obtained by the numerical simulations for various values of entering parameters.

Fig. 1 clearly demonstrates that the velocity decreases with an increase in the $M$. The magnetic parameter is found to retard the velocity at all points of the flow field. It is because that the application of transverse magnetic field will result in a resistive type force (Lorentz force) similar to drag force which tends to resist the fluid flow and thus reducing its velocity. Also the boundary layer thickness decreases with an increase in the magnetic field. Similar effect is also observed in Fig. 4 with the increase of rotational parameter. From Figs. 2 and 3 it is observed that the primary velocity profile increases with increase of Hall parameter and heat generation parameter. Secondary velocity decreases for the effect of stretching ratio which are shown in Fig. 8 whereas reverse trend are arises in Figs. 5-7 for the effect of magnetic, Hall and rotational parameter. Figs. 9-12 show the temperature profiles obtained by the numerical simulations for various values of entering parameters. From these Figs. it is observed that the thermal boundary layer decreases with the increase of values of mentioned parameters. Figs. 13-18 show the concentration profiles obtained by the numerical simulation for various values of entering non-dimensional parameters. In Fig. 16 the effect of $\mathrm{Sc}$ is found to decrease the concentration because increasing in Sc decreases molecular diffusivity which results in a decrease of the boundary layer. Hence the concentration of the species is lower for large values of Sc. Similar results are shown in Figs. 13-17 for the effect of magnetic parameter, rotational parameter and stretching ratio. The concentration is increased for the increasing values of heat generation parameter and Dufour number which are depicted in Figs. 15-18. Again, from Table 1 it is observed that the skin friction decreases for magnetic and rotation parameter but increases for heat generation parameter. The rate of heat transfer increases for magnetic, rotation parameter and heat generation parameters and Prandtl number as a result the thermal boundary layer is decreased. Again, the rate of concentration increases for magnetic parameter and Schmidt number as a result the concentration boundary layer is decreased but reverse case arised for heat generation parameter. 


\section{MHD Boundary Layer Flow of Heat and Mass Transfer}

Table 1. The skin friction $f^{\prime}(0)$, rate of heat transfer $-\theta^{\prime}(0)$ and rate of concentration $-\varphi^{\prime}(0)$ for different values of M, Q, Pr and Sc respectively.

\begin{tabular}{llllllll}
\hline$M$ & $Q$ & $R$ & $P r$ & $S c$ & $f^{\prime}(0)$ & $\theta^{\prime}(0)$ & $\varphi^{\prime}(0)$ \\
\hline $\mathbf{0 . 7}$ & 1.5 & 1.0 & 1.0 & 0.22 & -1.328837 & 1.388912 & 0.45214 \\
$\mathbf{1 . 0}$ & 1.5 & 1.0 & 1.0 & 0.22 & -1.493299 & 1.394635 & 0.46072 \\
$\mathbf{1 . 5}$ & 1.5 & 1.0 & 1.0 & 0.22 & -1.642638 & 1.413526 & 0.47594 \\
0.5 & $\mathbf{0 . 5}$ & 1.0 & 1.0 & 0.22 & -1.397322 & 0.981208 & 0.65231 \\
0.5 & $\mathbf{1 . 0}$ & 1.0 & 1.0 & 0.22 & -1.368509 & 1.324562 & 0.63215 \\
0.5 & 1.5 & 1.2 & 1.0 & 0.22 & -1.380072 & 1.389255 & - \\
0.5 & 1.5 & $\mathbf{1 . 4}$ & 1.0 & 0.22 & -1.423595 & 1.389718 & - \\
0.5 & 1.5 & 1.0 & 2.0 & 0.22 & - & 1.548451 & - \\
0.5 & 1.5 & 1.0 & 3.0 & 0.22 & - & 1.699187 & - \\
0.5 & 1.5 & 1.0 & 1.0 & $\mathbf{0 . 4 4}$ & - & - & 0.63533 \\
0.5 & 1.5 & 1.0 & 1.0 & $\mathbf{0 . 6 6}$ & - & - & 0.77595 \\
\hline
\end{tabular}

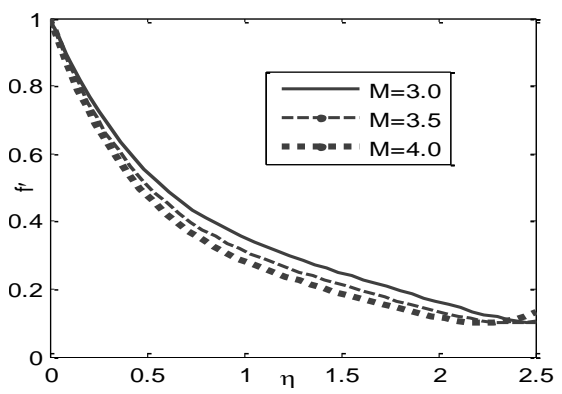

Fig. 1. Primary velocity profile for M.

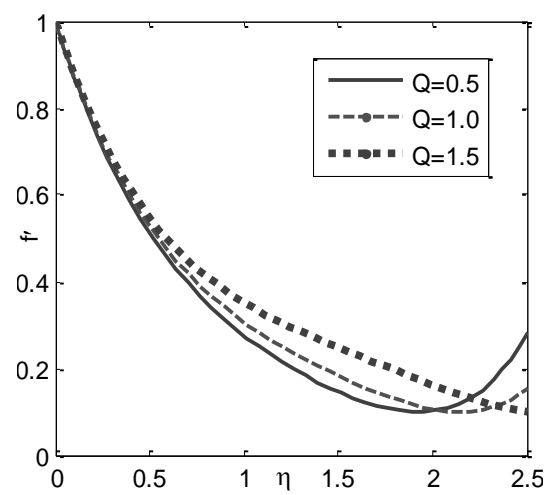

Fig. 3. Primary velocity profile for Q.

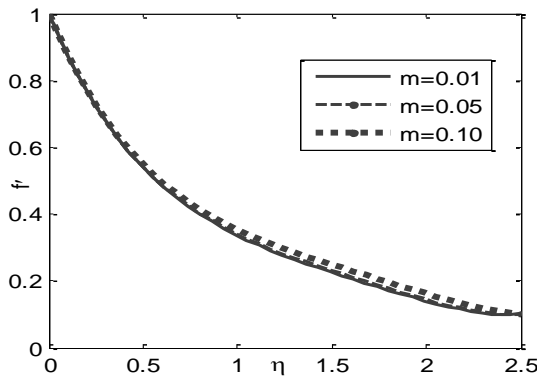

Fig. 2. Primary velocity profile for $\mathrm{m}$.

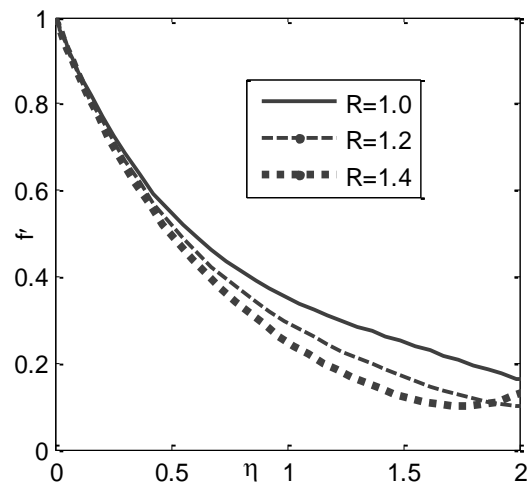

Fig. 4. Primary velocity profile for R. 

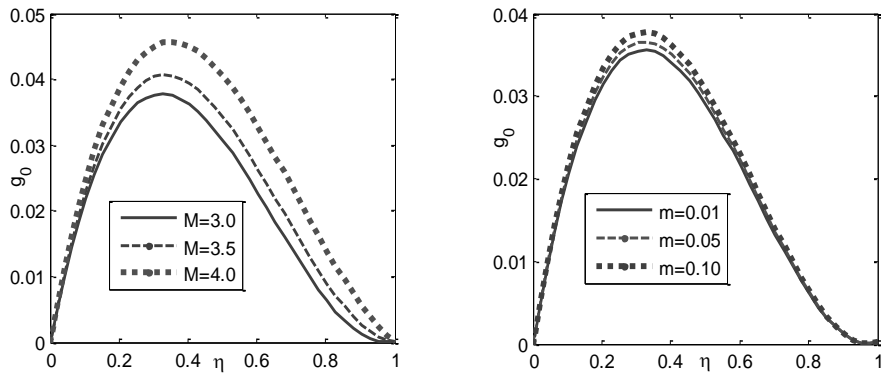

Fig. 5. Secondary velocity profile for M.

Fig. 6. Secondary velocity profile for $\mathrm{m}$.
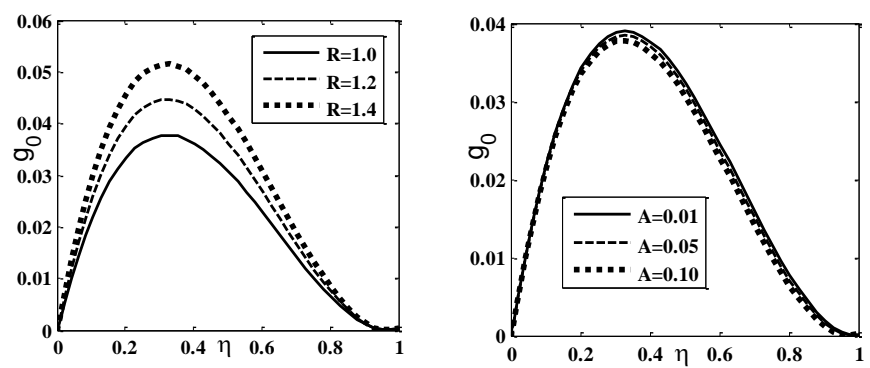

Fig. 7. Secondary velocity profile for R.

Fig. 8. Secondary velocity profile for A.
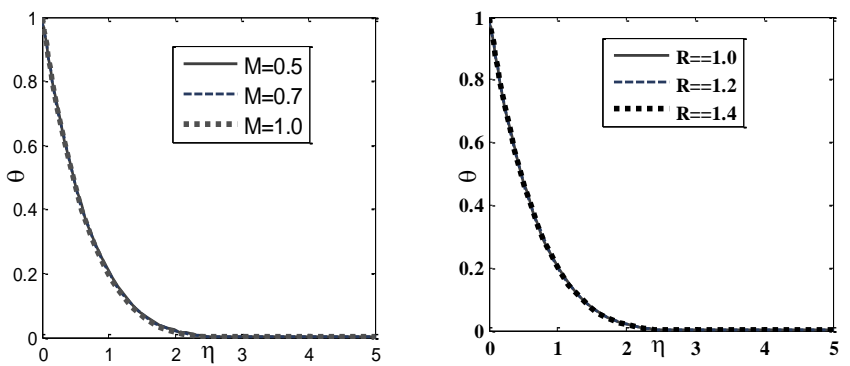

Fig. 9. Temperature profile for M.

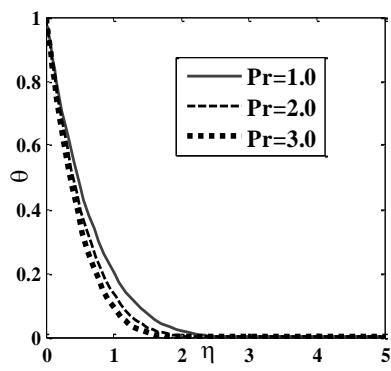

Fig. 10. Temperature profile for $\mathrm{R}$.

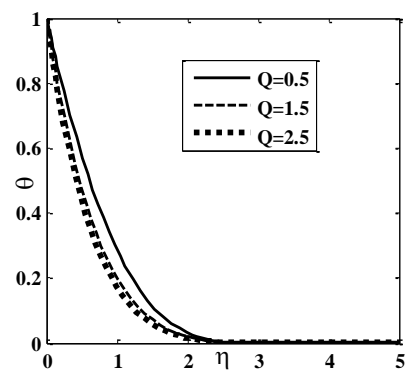

Fig. 11. Temperature profile for Pr.

Fig. 12. Temperature profile for $\mathrm{Q}$. 


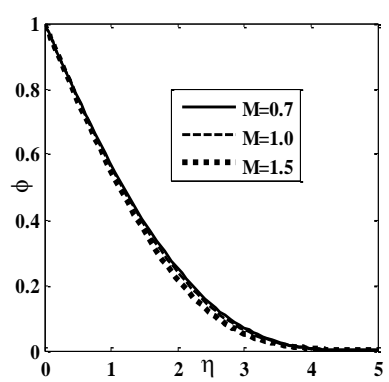

Fig. 13. Concentration profile for M.

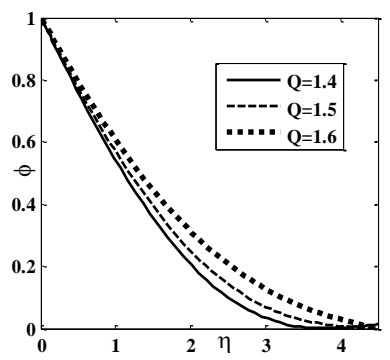

Fig. 15. Concentration profile for $\mathrm{Q}$.

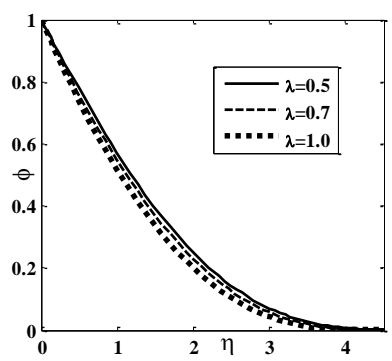

Fig. 17. Concentration profile for $\lambda$.

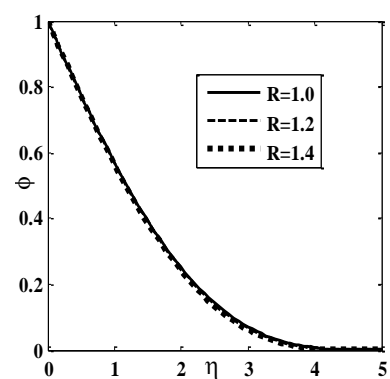

Fig. 14. Concentration profile for R.

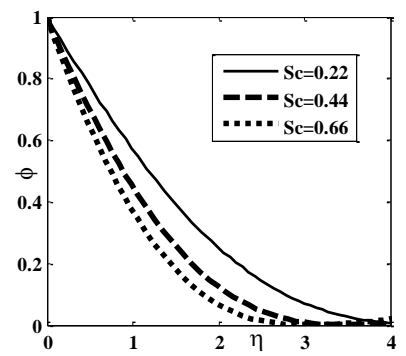

Fig. 16. Concentration profile for Sc.

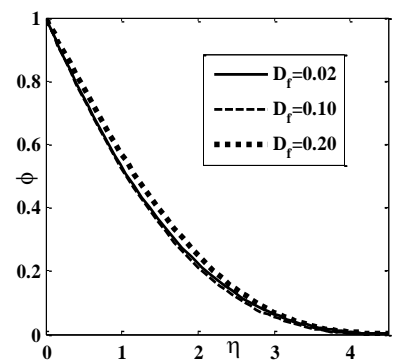

Fig. 18. Concentration profile for $\mathrm{D}_{\mathrm{f}}$.

\section{Conclusion}

The results are presented to display the flow characteristic like velocities, temperature and concentration. Followings are the conclusions made from above analysis:

- The magnitude of velocity is decreased with increasing magnetic parameter because of Lorentz force. Also for the influence of rotational parameter velocity decreased, it is interesting to note that for large rotation the maximum velocity occured near the plate.

- $\quad$ The secondary velocity is increased for increasing values of magnetic, Hall and rotational parameter. 
- $\quad$ The temperature decreased with an increase in the Prandtl number, which implied that viscous boundary layer is thicker than the thermal boundary layer. From these plots it is evident that large values of Prandtl number resulted in thinning of the thermal boundary layer. In this case temperature asymptotically approached to zero in free stream region. Also similar results arised for magnetic, heat generation and rotational parameter.

- $\quad$ The effect of Sc is found to decrease the concentration because increasing Sc decreased molecular diffusivity which resulted in a decrease of the boundary layer. Hence the concentration of the species is lower for large values of Sc, similar effect arised for magnetic parameter, rotational parameter and stretching ratio.

\begin{tabular}{|c|c|c|c|}
\hline $\begin{array}{l}\text { MHD } \\
c_{p}\end{array}$ & $\begin{array}{l}\text { Magneto hydrodynamics } \\
\text { Specific heat of with constant }\end{array}$ & $\beta^{*}$ & $\begin{array}{l}\text { Coefficient of expansion with } \\
\text { concentration }\end{array}$ \\
\hline & pressure & $\rho$ & Density \\
\hline $\mathrm{g}$ & Gravitational acceleration & $\sigma$ & Fluid electrical conductivity \\
\hline$g_{0}$ & Secondary Velocity & $\theta$ & Dimensionless temperature \\
\hline$f^{\prime}$ & $\begin{array}{l}\text { Velocity Profile } \\
\text { Magnetic }\end{array}$ & $\mathrm{u}$ & $\begin{array}{l}\text { Velocity component in } \mathrm{x} \text { - } \\
\text { direction }\end{array}$ \\
\hline M & $\mathrm{M}=\frac{2 \mathrm{x} \sigma \mathrm{B}_{0}^{2}}{}$ & $\mathrm{v}$ & $\begin{array}{l}\text { Velocity component in } y- \\
\text { direction }\end{array}$ \\
\hline & $\rho \mathrm{U}_{0}$ & W & Secondary Velocity \\
\hline $\mathrm{m}$ & Hall parameter & $\mathrm{T}$ & Temperature \\
\hline$v$ & Kinematic viscosity & $\mathrm{k}_{0}$ & Coefficient of concentration \\
\hline$\eta$ & Similarity variable & $\mathrm{D}_{\mathrm{m}}$ & Thermal molecular diffusivity \\
\hline$\alpha$ & $\begin{array}{l}\text { Thermal } \\
\alpha=\frac{\mathrm{k}}{}\end{array}$ & $\begin{array}{l}\mathrm{D} \\
\mathrm{C}_{\mathrm{s}} \\
\mathrm{k}\end{array}$ & $\begin{array}{l}\text { Mass diffusion coefficient } \\
\text { Concentration susceptibility } \\
\text { Thermal conductivity }\end{array}$ \\
\hline$\beta$ & $\begin{array}{l}\rho c_{p} \\
\text { Thermal }\end{array}$ & $C_{x}$ & $\begin{array}{l}\text { Concentration of the fluid } \\
\text { outside the boundary layer }\end{array}$ \\
\hline & Coefficient & & \\
\hline
\end{tabular}

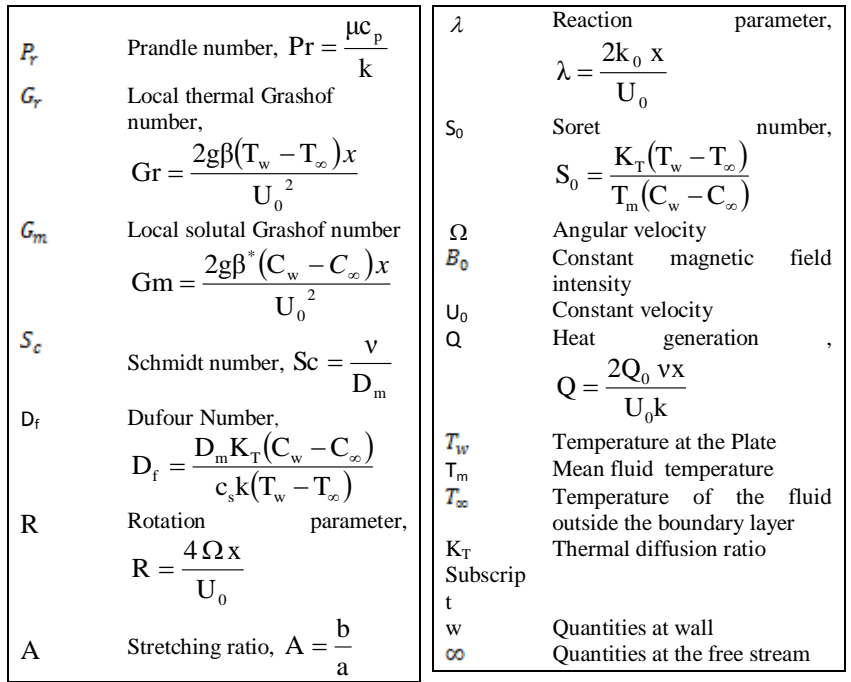




\section{References}

1. M. Ali and M. S. Alam, J. Sci. Res. 6(3), 457 (2014).

http://dx.doi.org/10.3329/jsr.v6i3.16903

2. M. M. Rahman, M. A. Alim, and M. K. Chowdhury, J. Sci. Res. 1(3), 461 (2009). http://dx.doi.org/10.3329/jsr.v1i3.2597

3. D. R. Kuiry and S. Bahadur, J. Sci. Res. 7(3), 21 (2015). http://dx.doi.org/10.3329/jsr.v7i3.22574

4. S. F. Ahmmed and M. S. A. Sarker, J. Sci. Res. 2(3), 453 (2010). http://dx.doi.org/10.3329/jsr.v2i3.4776

5. M. G. Reddy, J. Sci. Res. 6(2), 257 (2014). http://dx.doi.org/10.3329/jsr.v6i2.17233

6. R. Kumar and K. D. Singh, Int. J. Appl. Math. Mech. 8(6), 49 (2012).

7. M. S. Alam, M. Ali, and M. A. Alim, J. Sci. Res. 8(1), 41 (2016). http://dx.doi.org/10.3329/jsr.v8i1.25599

8. S. Parvin, R. Nasrin, M. A. Alim, and N. F. Hossain, J. Sci. Res. 5(1), 67 (2013). http://dx.doi.org/10.3329/jsr.v5i1.9641

9. M. S. Alam, M. Ali, M. A. Alim, and A. Saha, J. Sci. Ind. Res. 49, 155 (2014). http://dx.doi.org/10.3329/bjsir.v49i3.22129

10. U. Mishra and G. Singh, Heat Trans Asian Res. 43(5), 447 (2014). http://dx.doi.org/10.1002/htj.21088 